\title{
ANÁLISE DOS APONTAMENTOS DAS CONTAS PÚBLICAS EMITIDOS PELO TCE-MT DA UNIVERSIDADE DO ESTADO DE MATO GROSSO - UNEMAT
}

$\begin{array}{ll}\text { Nome } & \begin{array}{l}\text { Stela Rodrigues de Souza } \\ \text { Instituição/Afiliação } \\ \text { País }\end{array} \\ \begin{array}{ll}\text { Universidade do Estado de Mato Grosso } \\ \text { Nome }\end{array} \\ \begin{array}{l}\text { Instituição/Afiliação } \\ \text { País }\end{array} & \begin{array}{l}\text { Universidade do Estado de Mato Grosso (UNEMAT), Brasil } \\ \text { Brasil }\end{array} \\ \text { Nome } & \begin{array}{l}\text { Margarida Alves Rocha } \\ \text { Instituição/Afiliação } \\ \text { País }\end{array}\end{array}$

\section{RESUMO}

O presente artigo tem como objetivo a análise dos relatórios técnicos anual, das contas públicas da Universidade do Estado de Mato Grosso, UNEMAT, emitidos pelo Tribunal de Contas do estado de Mato Grosso, TCE-MT, dos anos de 2006 à 2014. A pesquisa é de natureza descritiva e de caráter qualitativo, utilizando de fontes bibliográficas e documentos eletrônicos, para obtenção dos dados secundários para elaboração do estudo. A partir daí, levantou-se a quantidade de irregularidades ocorridas em cada ano, a fim de comparar a evolução dos apontamentos nos períodos. Com um total de 316 irregularidades apontadas nesses anos, os apontamentos são classificados segundo a natureza gravíssima, grave, moderada e não classificada e, de acordo com o assunto de cada irregularidade. Após a realização da análise, verifica-se que a quantidade de irregularidades total por período, tem tido alguns acréscimos em comparação ao ano anterior, porém nos dois últimos anos, a quantidade tem diminuído significativamente, indicando que houve melhoras nas contas anuais de gestão da UNEMAT.

Palavras-chave: Irregularidades. Pareceres. Prestação de contas

\begin{abstract}
The present article has the aim to analyze the annual technical reports of public accounts of the Universidade do Estado de Mato Grosso (University of Mato Grosso State) UNEMAT, issued by the Tribunal de Contas (Audit Office) of Mato Grosso State - TCE-MT, from 2006 to 2014. The research has descriptive nature and qualitative character, using bibliographical sources and electronic documents to find secondary data for the study elaboration. From this, it was listed the amount of irregularities that occurred each year, in order to compare the evolution of notes in the mentioned periods. With a total of 316 irregularities pointed out in this years, the notes are classified according to the nature: extremely serious, serious, moderate and not classified and also, according to the subject of each irregularity. After the analysis, it was verified that the
\end{abstract}


amount of total irregularities by period has had some increases in relation to the previous year, however in the two last years the amount has decreased significantly, indicating that there were improvements in the annual accounts management of UNEMAT.

Keywords: Irregularities. Opinions. Accountability.

\section{INTRODUÇÃO}

Criados pela Constituição de 1891, os Tribunais de Contas, são órgãos que têm por função controlar e fiscalizar os órgãos públicos, através de julgamentos técnicos das ações públicas (SILVA; REVORÊDO, 2005) e o resultado desse julgamento técnico, que é chamado parecer, é emitido através de relatórios.

Existem vários Tribunais de Contas no Brasil, o Tribunal de Contas da União, que exerce o papel de orientar o Congresso a respeito das contas dos órgãos federais, o Tribunal de Contas dos Estados, que tem por função principal julgar as contas dos órgãos estaduais e o Tribunal de Contas dos Municípios que julgam as contas municipais, esse é exceção para as cidades de São Paulo e Rio de Janeiro (CAPOBIANCO, 2012).

O Tribunal de Contas do Estado do Mato Grosso, TCE-MT, de acordo com seu site do Portal do TCE-MT, tem por missão controlar a gestão dos recursos públicos dos órgãos do Estado de Mato Grosso, através de avaliação de desempenho, fiscalização e julgamento. Conforme o que diz a Lei Complementar n. 269 de 2007, o TCE-MT, emite parecer prévio das contas prestadas anualmente pelo Governo do Estado e pelos Prefeitos Municipais.

Os apontamentos dos Tribunais de Contas nas contas públicas, são de grande importância na transparência da gestão pública brasileira. Segundo Loureiro, Teixeira e Prado (2008) a colocação do país na economia global e as exigências decorrentes de equilíbrio das contas públicas desencadeiam movimentos de reestruturação e modernização do Estado. Bezerra e Apolinário (2014) afirmam que os pareceres dos Tribunais de Contas colaboram com a melhoria do desempenho do Estado, pois através deles é permitido à sociedade exercer o seu direito de cidadania.

Conforme Neto, Cruz e Vieira (2006) o ordenamento jurídico prevê várias normas que regulamentam a prestação de contas dos gestores públicos ao poder público e à população em geral. Sendo a Universidade do Estado de Mato Grosso, UNEMAT, um ente da administração indireta, suas contas estão sujeitas aos apontamentos e pareceres do TCE-MT, o qual emite seus 


\section{Revista

apontamentos. Com essa base, será efetuado uma análise nos relatórios anuais emitidos, nos anos de 2006 à 2014.

A Universidade do Estado do Mato Grosso, UNEMAT, é uma fundação de ensino superior na qual, as contas passam pela auditoria técnica do TCE-MT, que registra seus resultados nos relatórios anuais. Houve quatro gestões na UNEMAT nos períodos analisados sendo que cada gestão tem permanência de quatro anos, após esse período, a comunidade acadêmica reelege ou elege um novo reitor.

De outubro de 2002 a setembro de 2010 foi a gestão de Taisir Mahamudo Karin, esse reitor foi escolhido pela comunidade acadêmica por dois mandatos consecutivos, ficando na gestão por oito anos. De outubro de 2010 a fevereiro de 2014 a universidade teve como reitor Adriano Aparecido Silva, que também foi escolhido pela comunidade acadêmica. Em fevereiro de 2014, assumiu o cargo de reitoria Dionei José da Silva, que substituiu o titular que se afastou para concorrer às eleições estaduais; sua gestão foi até dezembro de 2014.

A pesquisa inicia-se a partir da seguinte questão problema: Qual a situação das contas públicas da Universidade do Estado de Mato Grosso, UNEMAT, segundo os relatórios técnicos anuais emitidos pelo Tribunal de Contas do Estado de Mato Grosso, TCE-MT, nos anos de 2006 a $2014 ?$

O objetivo geral da pesquisa é analisar os relatórios técnicos anuais, emitidos pelo TCE-MT, para a UNEMAT, dos anos de 2006 à 2014, demonstrando se houve evoluções nos apontamentos; e como objetivos específicos, verificar as irregularidades apontadas pela equipe técnica de auditores públicos, responsáveis pelo relatório dos anos analisados; apresentar os apontamentos de irregularidades nas contas públicas no decorrer dos anos.

Justifica-se a pesquisa por sua relevância, contribuição e oportunidade. A relevância está relacionada, com a necessidade de identificar as falhas apontadas pelo TCE-MT, nas contas anuais da UNEMAT e de demonstrar qual o grau de gravidade de cada uma delas. A pesquisa visa contribuir, com o meio acadêmico e social em geral, auxiliando assim, para uma compreensão melhor das pessoas nos apontamentos, trazendo a oportunidade para a universidade de evitar possíveis falhas e obter maior credibilidade perante os acadêmicos e população em geral, comprovando mais comprometimento e seriedade como instituição pública. 


\section{REFERENCIAL TEÓRICO}

A seguir, será apresentada a base teórica que foi utilizada para o desenvolvimento da pesquisa.

\subsection{A Importância da Transparência na Gestão Pública}

As instituições que compõem a administração pública brasileira são obrigadas pela Constituição Federal, a prestar contas da utilização de recursos públicos e a respeitar o princípio da publicidade, entre outros princípios da administração pública (NETO et al., 2007). A partir disso, criou-se no Brasil várias leis, com o objetivo de estabelecer aspectos de melhoramento na administração das contas públicas.

Uma dessas leis é a Lei Complementar ${ }^{\circ} 101$ de 2000, mais conhecida como Lei de Responsabilidade Fiscal (LRF) que, segundo Sodré (2002), visa principalmente a disciplina fiscal, ainda de acordo com Neto, Cruz e Vieira (2006), a LRF baseia-se em alguns conceitos como o planejamento, a transparência e a participação popular. Os autores afirmam que a transparência é um princípio da gestão fiscal responsável e como tal, implica na publicidade e na compreensão das informações.

De acordo com Neto et. al. (2007), o conceito de transparência na administração pública é muito amplo, já que garante o atendimento das normas legais, além de constituir também, uma política de gerenciamento responsável, que favorece o exercício da cidadania pelas pessoas.

\subsection{Tribunais de Contas no Brasil}

A ideia de se criar um órgão público fiscalizador, segundo Ramalho (2011), surgiu ainda no Brasil Império aproximadamente em 1826, mas só em 1845, através do Ministro do Império Manuel Alves Branco, foi criado um Tribunal que exercia o papel de fiscalizar e apurar 
a responsabilidade dos gestores da Fazenda Pública, contudo não houve sucesso nessa primeira iniciativa.

Em 1890, Rui Barbosa redigiu o Decreto 966-A, que propunha a criação de um serviço intermediário à administração e a legislatura, com o objetivo de revisar e julgar os atos da administração praticados pelos agentes públicos, porém somente em 1891, foi criado o Tribunal de Contas (SILVA; REVORÊDO, 2005).

Atualmente, os Tribunais de Contas exercem a função de fiscalizar os entes federativos da administração pública direta e indireta, bem como as empresas públicas e as sociedades de economia mista, essa fiscalização é contábil, financeira, orçamentária, operacional e patrimonial (MELO, 2012).

O Tribunal de Contas do Estado do Mato Grosso, é regido pela Lei Complementar $\mathrm{n}^{\circ}$ 269, de 22 de janeiro de 2007, a qual dispõe sobre o TCE-MT e dá outras providências. No artigo $1^{\circ}, \S 1^{\circ}$, dessa Lei Complementar é disposto que:

\$1. No julgamento de contas e na fiscalização que lhe compete, o Tribunal decidirá sobre a legalidade, a legitimidade, a eficiência e a economicidade dos atos de gestão e das despesas deles decorrentes, bem como sobre a aplicação de subvenções e a renúncia de receitas. (MATO GROSSO 2007).

Conforme Menezes (2012) os Tribunais de Contas são órgãos auxiliares do poder Legislativo que possuem um corpo técnico qualificado, priorizando o cumprimento da lei. Resumidamente os Tribunais de Contas, sejam eles pertencentes aos níveis federal, estadual e municipal exercem importantes funções e atribuições de natureza administrativa e constitucional (RAMALHO 2011).

\subsection{Apontamentos e pareceres do Tribunal de Contas do Estado do Mato Grosso}

Os Tribunais de Contas do Brasil, exercem função fiscalizadora em todos os órgãos públicos, por isso todos os anos é emitido um parecer dos TC nas contas anuais dos órgãos da administração pública em forma de relatório, chamado também de apontamentos. Portanto, anualmente, o poder executivo, através de seus representantes, apresenta suas contas ao Tribunal de Contas, o qual emitirá pareceres favoráveis, ou não, da utilização dos recursos em suas contas apresentadas (RAMALHO, 2011). 
De acordo com a Lei Complementar $\mathrm{n}^{\circ}$ 269, de 22 de janeiro de 2007, as contas poderão ser julgadas como sendo Contas Regulares, Contas Regulares com recomendações e/ou determinações legais, Contas Irregulares e Contas Iliquidáveis. Cada tipo de julgamento, o TCE-MT adota uma medida, com o intuito de disciplinar o órgão e os responsáveis pela apresentação das contas públicas, como descreve o quadro 1 .

Quadro 1 - Tipos de Julgamento das Contas Públicas pelo Tribunal de Contas do Estado do Mato Grosso

\begin{tabular}{|l|l|}
\hline \multicolumn{1}{|c|}{ Tipos de julgamento } & \multicolumn{1}{c|}{$\begin{array}{c}\text { Decisões do Tribunal de Contas do Estado do } \\
\text { Mato Grosso }\end{array}$} \\
\hline Contas Regulares & $\begin{array}{l}\text { Art. 20 Quando as contas forem julgadas regulares, o } \\
\text { Tribunal de Contas dará quitação plena ao } \\
\text { responsável. }\end{array}$ \\
\hline $\begin{array}{l}\text { Contas Regulares com recomendações e/ou } \\
\text { determinações legais }\end{array}$ & $\begin{array}{l}\text { Art. 21 Quando as contas forem julgadas regulares } \\
\text { com recomendações e/ou determinações legais, sem } \\
\text { aplicação de multa, o Tribunal de Contas dará } \\
\text { quitação ao responsável, com as observações que } \\
\text { entender necessárias. }\end{array}$ \\
\hline Contas Irregulares & $\begin{array}{l}\text { Art. 23 Quando julgar as contas irregulares, havendo } \\
\text { débito, o Tribunal condenará o responsável ao } \\
\text { pagamento da dívida atualizada, sem prejuízo da } \\
\text { aplicação de multa de acordo com a ocorrência } \\
\text { verificada, e observado o disposto no art. 80 desta lei. }\end{array}$ \\
\hline Contas Iliquidáveis & $\begin{array}{l}\text { Art. 24 Quando julgar as contas iliquidáveis, o } \\
\text { Tribunal ordenará o seu trancamento e o consequente } \\
\text { arquivamento do processo. }\end{array}$ \\
\hline
\end{tabular}

Fonte: Adaptada de Mato Grosso (2007).

Ainda conforme a LC 269/2007, são aplicadas multas, caso haja algum ato irregular, conforme o que diz a lei em seu artigo 74 e 75. A multa pode variar de 0 até 1000 Unidade Padrão Fiscal de Mato Grosso UPF-MT, e também pode ser aplicada a pessoa física responsável pelo ato ilegal, de forma individual responsabilizando cada agente que tiver praticado ou concordado com a ilegalidade cometida; a lei ressalta ainda, que todo o dinheiro arrecadado do pagamento dessas multas vai para o Fundo de Reaparelhamento e Modernização do Tribunal de Contas do Estado, criado pela Lei 8.411, de 27/12/2005, nos termos regimentais (MATO GROSSO, 2007). 


\subsubsection{Classificação das Irregularidades das Contas Anuais}

O TCE-MT adota alguns critérios para classificar as irregularidades detectadas nas contas públicas do órgão auditado. Esses critérios estão descritos em um manual do TCE-MT, e publicado em seu portal. No manual é retratado com detalhes, os tipos de irregularidades que estão em desacordo com Constituição Federal de 1988 e com a Lei Complementar nº 101/2000. A conclusão do TCE-MT nos pareceres de auditoria, são descritos de acordo com o Assunto e a Natureza da Irregularidade.

O Assunto indica a matéria da irregularidade encontrada e é apresentado na classificação da mesma por código, sendo o primeiro dígito para identificação da irregularidade (MATO GROSSO, 2015); é classificado e codificado conforme o quadro 2.

Quadro 2 - Forma de classificação do Assunto da Irregularidade apontad
\begin{tabular}{|l|l|}
\hline Código & \multicolumn{1}{c|}{ Assunto } \\
\hline A & Limites Constitucionais/Legais \\
\hline B & Gestão Patrimonial \\
\hline C & Contabilidade \\
\hline D & Gestão Fiscal/Financeira \\
\hline E & Controle Interno \\
\hline F & Planejamento/Orçamento \\
\hline G & Licitação \\
\hline H & Contrato \\
\hline I & Convênio \\
\hline J & Despesa \\
\hline K & Pessoal \\
\hline L & Regime Próprio de Previdência Social (RPPS) \\
\hline M & Prestação de Contas \\
\hline N & Diversos \\
\hline
\end{tabular}

Fonte: Adaptado de Mato Grosso (2015).

A Natureza da irregularidade identifica sua proporção, em conformidade com a legislação brasileira, e é apresentada em forma de código, sendo o segundo dígito na classificação da irregularidade. É dividida em três tipos, sendo usado "A" para identificação de 
irregularidades de natureza Gravíssimas, "B" para de natureza Graves e "C" para de natureza Moderadas (MATO GROSSO, 2015). É utilizado também como natureza da irregularidade as "Não Classificada", que são aquelas que não se enquadram em nenhuma natureza e assunto, descrito no manual do TCE-MT.

Dentro da Natureza é descrita exatamente, a irregularidade apontada, ficando explícito o descumprimento da legislação. Por exemplo: quando o TCE-MT aponta uma conta como sendo AA 01. Limite Constitucional/Legal_Gravíssima_01, significa a "Não-aplicação do percentual mínimo de $25 \%$ da receita de impostos, compreendida a proveniente de transferências, na manutenção e desenvolvimento do ensino" (art. 212, da Constituição Federal).

\subsection{Estudos relacionados ao tema da pesquisa}

Existem diversos estudos dos relatórios das contas públicas de um determinado órgão, emitidos pelos Tribunais de Contas no país. Silva (2010) realizou um estudo sobre o novo papel dos Tribunais de Contas no julgamento das Contas do Governo, feito sobre o município de Fortaleza nos anos de 2005 à 2009. Após o estudo foi concluído que é preciso melhorar a qualidade do gasto público de forma consistente com o equilíbrio fiscal para abrir espaço para investimentos e gastos sociais e se obter resultados de eficiência, eficácia e efetividade.

Cabral e Ribeiro (2012), analisaram os apontamentos do TCE-MT nas Contas Públicas dos municípios da região médio-norte do Mato Grosso e concluíram que, as irregularidades apresentadas por essas gestões municipais, não atendem os dispositivos da transparência e equilíbrio das receitas e despesas trazidas na Lei Complementar 101/2000, colocando em dúvidas, a gestão fiscal e responsável dessas gestões.

Bezerra e Apolinário (2014), fez um estudou sobre a Prestação de Contas em Pareceres Prévios do Tribunal de Contas da Paraíba. Os resultados dessa pesquisa apontaram que a dimensão formal da prestação de contas foi totalmente considerada, enquanto a dimensão substantiva apenas parcialmente, visto que somente os aspectos legais são explorados em totalidade.

Macêdo e Costa (2014), levantaram uma análise do conteúdo informativo dos pareceres dos auditores dos Tribunais de Contas dos Estados Brasileiros. Após a análise, concluiu-se que existem desacordos no conteúdo informacional dos pareceres prévios dos 


\section{Revista \\ UNEMAT de \\ Contabilidade}

tribunais de contas dos estados brasileiros e verificou-se que os gestores públicos das unidades federativas do Brasil descumpriram em alguns quesitos, a Lei $\mathrm{n}^{\mathbf{0}}$ 4.320/1964, a Lei Complementar 101/2000 e a Constituição Federal.

\section{METODOLOGIA}

A presente pesquisa é um estudo do caso da UNEMAT. Conforme Andrade (2008), o estudo de caso busca abranger a totalidade de uma situação, descrevendo, compreendendo e interpretando um caso, através de um estudo detalhado de um objeto delimitado. É de natureza qualitativa e de caráter descritivo. Segundo Martins (2004), uma pesquisa qualitativa é aquela que foca na análise do processo, através de estudo detalhado dos dados. A pesquisa descritiva busca descrever, classificar e interpretar os dados, ou fatos, descobertos ou observados, para a elaboração da pesquisa (VIEIRA, 2002).

A pesquisa utiliza-se de fontes bibliográficas, para a elaboração da base teórica. $\mathrm{O}$ estudo bibliográfico é constituído através da observação das etapas, de leitura e de questionamentos com o material bibliográfico (SASSO; TAMASO, 2007). É utilizado também documentos eletrônicos, para obtenção dos elementos para a análise dos dados. Entre esses documentos eletrônicos estão os relatórios técnicos do TCE-MT da UNEMAT, Leis e outros estudos relacionados com a pesquisa.

Para o desenvolvimento do estudo, levantou-se a questão problema e os objetivos para atingir o resultado esperado. Essa pesquisa visa analisar os relatórios técnicos anuais, emitidos pelo TCE-MT, das contas públicas da UNEMAT, dos anos de 2006 à 2014, com o objetivo de identificar se houve melhora nos apontamentos, ou seja, analisar as irregularidades apontadas nos anos analisados, e verificar qual o nível de gravidade das mesmas.

Foi realizada a fundamentação teórica, para embasar e enfatizar o tema da pesquisa a partir de artigos científicos desenvolvidos nessa mesma linha, além de leis que serviram como base para sustentar as ideias de vários autores. Utilizou-se também, resultados de pesquisas relacionadas com pareceres, emitidos por diversos Tribunais de Contas no Brasil, para assim demonstrar e comparar o resultado que cada um obteve, a partir das análises dos relatórios de contas públicas anuais de vários órgãos no país.

Foram utilizados artigos científicos, publicados em revistas e/ou congressos para a elaboração da base científica. Para busca desses artigos, utilizou-se bibliotecas on-line como 
"Google Acadêmico" e "Redalyc", que é um portal onde se reúne diversas publicações científicas de várias revistas e congressos da América Latina.

A fonte para a coleta de dados é o portal do TCE-MT, no qual estão disponíveis os pareceres das contas da UNEMAT de acordo com cada ano analisado, 2006 a 2014, em forma de relatório. Neles estão contidas as informações necessárias para realização da pesquisa.

$\mathrm{Na}$ análise dos dados foram reunidas todas as irregularidades apontadas nos relatórios técnicos do TCE-MT antes da apresentação da defesa por parte da universidade e classificadas conforme a gravidade de cada uma, para assim comparar os anos analisados e então, chegar a conclusão se houve melhoras nos apontamentos, de acordo com os anos em questão. Utilizouse quadros e tabelas para demonstrar com mais clareza os resultados obtidos na pesquisa.

A pesquisa é delimitada a análise dos relatórios das contas públicas da Universidade do Estado do Mato Grosso, UNEMAT, segundo os pareceres dos auditores do Tribunal de Contas do Estado do Mato Grosso, TCE-MT, dos anos de 2006 à 2014. Esses pareceres estão disponíveis no portal do TCE-MT e a análise será feita com base nesses relatórios.

\section{RESULTADOS E DISCUSSÕES}

A seguir, será apresentado os resultados obtidos a partir dessa pesquisa e posteriormente, será feito as discussões e análise dos dados, para se atingir a resposta do problema da pesquisa e alcançar os objetivos propostos.

\subsection{Levantamento e análise dos dados da pesquisa}

Os dados da pesquisa foram coletados dos relatórios técnicos do TCE-MT, emitidos anualmente após auditoria das contas anuais da UNEMAT. Esses relatórios são divulgados publicamente no portal do TCE-MT, com objetivo de demonstrar qual a situação das contas públicas do órgão, perante os Pareceres Técnicos de acordo com a prestação de contas feita pelo Reitor da universidade.

$\mathrm{Na}$ tabela 1 foi levantada a quantidade de irregularidades apontadas pelos auditores técnicos do TCE-MT no período de 2006 a 2014. Demonstra também o percentual das irregularidades por ano analisado, sendo possível assim, visualizar quantos por cento equivale os apontamentos de cada período, em relação a soma, da quantidade de apontamentos, de todos 
os anos. Para a apuração da quantidade obtida, foi feita a análise dos relatórios ano a ano, antes da apresentação da defesa da universidade e agrupado conforme demonstra a tabela 1.

Tabela 1 - Quantidade de apontamentos irregulares do período de 2006 à 2014

\begin{tabular}{ccc}
\hline ANO & $\begin{array}{r}\text { Quantidade de } \\
\text { Apontamentos }\end{array}$ & Percentual \\
\hline 2006 & 58 & $18,35 \%$ \\
\hline 2007 & 59 & $18,67 \%$ \\
\hline 2008 & 44 & $13,92 \%$ \\
\hline 2009 & 33 & $10,44 \%$ \\
\hline 2010 & 50 & $15,82 \%$ \\
\hline 2011 & 16 & $5,06 \%$ \\
\hline 2012 & 41 & $12,97 \%$ \\
\hline 2013 & 12 & $3,80 \%$ \\
\hline 2014 & 3 & $0,95 \%$ \\
\hline TOTAL & 316 & $100 \%$ \\
\hline
\end{tabular}

Fonte: Dados da pesquisa $(201 \overline{7)}$

Ao observar a tabela 1, é possível verificar que a quantidade de irregularidades apontadas decresceu nos dois últimos anos analisados, sendo apontadas 12 irregularidades no período de 2013 e 3 no ano de 2014. Já em 2006, houve um total de 58 irregularidades apontadas e esse número aumentou em 2007 para 59. No ano de 2008 foram apontadas 44 irregularidades, com isso, é possível verificar a diminuição de 15 apontamentos em relação ao período de 2007.

Em 2009, verifica-se também que o número de irregularidades diminuiu para 33. No ano de 2010, as irregularidades apontadas aumentaram para 50. No período de 2011, o total de apontamentos foi 16, nesse período as irregularidades diminuíram significativamente comparado ao ano de 2010. Essa diminuição não ocorreu no ano de 2012, pelo contrário, foram encontradas 41 irregularidades. Em 2013 as irregularidades diminuíram em 13; e em 2014, houve um total de 3 apontamentos.

O aumento da quantidade de irregularidades em 2007, não foi tão considerável em relação ao ano anterior, já que o aumento equivale a 0,32\% em relação a 2006. Em 2008, verifica-se que as irregularidades decresceram 4,75\% comparado ao período antecedente. Em 2009, a quantidade de apontamentos que diminuíram foram de 3,48\%, em comparação ao ano de 2008. Já em 2010, houve um aumento significativo de 5,38\%, quando comparado ao ano de 2009. 


\section{Contabilidade}

Em 2011 as irregularidades apontadas diminuíram em relação aos períodos anteriores, sendo 10,76\% menor que o ano de 2010. Em 2012 as irregularidades tornaram a aumentar, ficando 7,91\% maior que o ano de 2011. Nos dois últimos anos as irregularidades decresceram; em 2013 diminuiu 9,17\% em relação a 2012 e em 2014 decresceu 2,85\% quando comparado ao período anterior.

\subsection{Análise dos apontamentos quanto a natureza e assunto}

Na tabela 2, apresenta-se a quantidade de irregularidades apontadas pelos auditores do TCE-MT, no período de 2006 à 2014, de acordo com sua natureza gravíssima, grave, moderada e não classificada.

Tabela 2 - Irregularidades apontadas de acordo com sua natureza no período de 2006 à 2014 da UNEMAT

\begin{tabular}{|c|c|c|c|c|c|}
\hline \multirow{2}{*}{ ANO } & \multicolumn{4}{|c|}{ NATUREZA } & \multirow{2}{*}{$\begin{array}{l}\text { Quantidade de } \\
\text { Irregularidades } \\
\text { Apontadas }\end{array}$} \\
\hline & Gravíssima & Grave & Moderada & Não Classificada & \\
\hline 2006 & - & 28 & - & 30 & 58 \\
\hline 2007 & - & 18 & - & 41 & 59 \\
\hline 2008 & - & 39 & - & 5 & 44 \\
\hline 2009 & - & 19 & - & 14 & 33 \\
\hline 2010 & - & 42 & 2 & 6 & 50 \\
\hline 2011 & 2 & 9 & 1 & 4 & 16 \\
\hline 2012 & - & 26 & 2 & 13 & 41 \\
\hline 2013 & - & 10 & 2 & - & 12 \\
\hline 2014 & - & 3 & - & - & 3 \\
\hline Total & 2 & 194 & 7 & 113 & 316 \\
\hline
\end{tabular}

Fonte: Dados da pesquisa (2017).

Verifica-se, que a maioria das irregularidades apontadas nesse período, um total de 194, foram de natureza grave e em todos os anos analisados houve apontamentos graves. As de natureza não classificada, também representa grande parte dos apontamentos, com um total de 113, porém não houve irregularidades não classificada apontadas nos dois últimos anos. As irregularidades de natureza moderadas foram 7, ocorridas no período de 2010 a 2013 e as de natureza gravíssima foram apontadas 2, ocorridas no ano de 2011, sendo uma de Gestão Patrimonial e outra de Controle Interno.

A tabela 3 demonstra a quantidade das irregularidades apontadas, quanto ao assunto de cada uma nos anos analisados. A classificação da irregularidade por assunto nas contas 


\section{Contabilidade}

públicas auditadas é feita com base em evidências do descumprimento ou inobservância da Constituição Federal, da Lei Complementar 101/2000 e de Leis e Normas Estaduais e Federais.

Tabela 3 - Irregularidades apontadas quanto ao assunto no período de 2006 a 2014 da UNEMAT

\begin{tabular}{|c|c|c|c|c|c|c|c|c|c|c|}
\hline \multirow[b]{2}{*}{ ASSUNTO } & \multicolumn{9}{|c|}{ ANO } & \multirow{2}{*}{$\begin{array}{c}\text { TOTA } \\
\mathbf{L} \\
\end{array}$} \\
\hline & 2006 & 2007 & 2008 & 2009 & 2010 & 2011 & 2012 & 2013 & 2014 & \\
\hline Gestão Patrimonial (B) & - & - & - & - & 1 & 1 & 4 & - & - & 6 \\
\hline Contabilidade $(\mathrm{C})$ & - & - & - & - & 3 & 1 & 4 & - & - & 8 \\
\hline $\begin{array}{l}\text { Gestão Fiscal / } \\
\text { Financeira (D) }\end{array}$ & - & - & - & - & 2 & - & 1 & - & 1 & 4 \\
\hline Controle Interno (E) & 28 & 17 & 39 & 19 & 7 & 2 & 2 & - & - & 114 \\
\hline $\begin{array}{l}\text { Planejamento / } \\
\text { Orçamento (F) }\end{array}$ & - & 1 & - & - & 4 & & 3 & - & - & 8 \\
\hline Licitação (G) & - & - & - & - & 5 & 1 & 2 & 5 & 1 & 14 \\
\hline Contrato $(\mathrm{H})$ & - & - & - & - & 3 & 1 & 3 & 4 & - & 11 \\
\hline Convênio (I) & - & - & - & - & 1 & - & 1 & - & - & 2 \\
\hline Despesa $(\mathrm{J})$ & - & - & - & - & 11 & 5 & 7 & 3 & 1 & 27 \\
\hline Pessoal (K) & - & - & - & - & 4 & - & 3 & - & - & 7 \\
\hline Prestação de Contas (M) & - & - & - & - & 2 & 1 & - & - & - & 3 \\
\hline Diversos $(\mathrm{N})$ & 30 & 41 & 5 & 14 & 7 & 4 & 11 & - & - & 112 \\
\hline $\begin{array}{c}\text { Quantidade de } \\
\text { Irregularidades } \\
\text { Apontadas por ano } \\
\end{array}$ & 58 & 59 & 44 & 33 & 50 & 16 & 41 & 12 & 3 & 316 \\
\hline
\end{tabular}

Fonte: Dados da pesquisa.

Observa-se que o assunto que ocorreu mais irregularidade foi no Controle Interno, onde houve 114 apontamentos e nos assuntos Diversos que ocorreram 112 irregularidades. Isso significa que a maioria das irregularidades de Controle Interno, estão ligadas diretamente a falhas no sistema administrativo da universidade; o que ocasiona essas irregularidades são o não cumprimento das metas, orçamentos e normas infringidas pelos gestores (MATO GROSSO, 2007). A partir do estudo do conteúdo informativo dos pareceres dos Tribunais de Contas, realizado nas unidades federativas do Brasil, Macêdo e Costa (2014) observaram também, que há uma necessidade de melhoria do controle interno por parte dos gestores públicos.

As irregularidades de assuntos Diversos são aquelas, que não existem uma classificação específica que caracterize a falha, desse modo, os auditores apenas descrevem as infrações cometidas no órgão, baseado no descumprimento de leis e normas. 
As irregularidades caracterizadas como de Gestão Patrimonial foram 6, sendo uma apontada em 2010 de natureza grave, uma em 2011 de natureza gravíssima e quatro apontamentos em 2012, todos de natureza grave. O apontamento ocorrido em 2010 e dois apontamentos ocorridos em 2012, indicaram falhas no registro de bens de caráter permanente, infringindo o art. 94 da Lei 4.320/1964. Já a irregularidade ocorrida em 2011 fere o art. 37 da Constituição Federal, significando que houve evidências de desvio de bens e/ou recursos públicos.

Uma das irregularidades ocorridas em 2012 é de despesas ilegais lesivas ao patrimônio público, violando o art. 15 da Lei Complementar 101/2000. Essa irregularidade se refere a locação de vários veículos, representando um gasto anual muito elevado contrariando o princípio da economicidade previsto na Constituição Federal de 1988. Outra irregularidade ocorreu pela realização de despesas com dispensa de licitação, isso vai contra os arts. 24 e 25 da Lei 8.666/1993.

Foram 8 as irregularidades na Contabilidade, sendo que três ocorreram em 2010, uma em 2011 e quatro em 2012; todas esses apontamentos infringem os arts. 83 a 106 da Lei 4.320/1964. Os apontamentos de irregularidades que aconteceram em 2010 e dois apontamentos de 2012, indicam falhas nos registros contábeis. A irregularidade ocorrida em 2011 e duas ocorridas em 2012 se deram, pela não contabilização de atos e fatos contábeis relevantes, ocasionando inconsistências nas demonstrações contábeis.

As irregularidades de Gestão Fiscal / Financeira foram 4, todas de natureza grave, sendo duas ocorridas em 2010, uma ocorrida em 2012 e outra ocorrida em 2014. Um dos apontamentos ocorridos em 2010 se deu pela inadimplência no pagamento da contribuição patronal, em desconformidade com os arts. 29 e 37 da Lei Complementar 101/2000 e outras leis e normas federais e estaduais. A outra irregularidade ocorrida em 2010, aconteceu por não existir retenção de tributos obrigatórios no pagamento de fornecedores.

Em 2012, a irregularidade de Gestão Fiscal / Financeira foi apontada por ter sucedido cancelamento de restos a pagar sem comprovação do motivo, infringindo o art. 37 da Constituição Federal. A irregularidade ocorrida em 2014 foi motivada, por não ter sido disponibilizado ao público, por meios eletrônicos, em tempo real, informações sobre a execução orçamentária e financeira, como prevê o art. 48 da Lei Complementar 101/2000.

Cabral e Ribeiro (2012), em sua análise sobre os apontamentos do TCE-MT nas contas públicas dos municípios da região médio-norte do estado de Mato Grosso, identificaram 40 
irregularidades de gestão fiscal só no ano de 2007, um número muito mais elevado que os apontamentos feitos na UNEMAT que totalizaram 4, nos nove anos analisados.

Ocorreram 8 apontamentos do assunto Planejamento / Orçamento, sendo que um ocorreu em 2007, quatro ocorreram em 2010 e três ocorreram em 2012; todos são de natureza grave. A causa da irregularidade do ano de 2007, foi a autorização para abertura de créditos adicionais ilimitados, violando o art. 167 da Constituição Federal. Uma das irregularidades que aconteceu em 2010 foi abertura de créditos adicionais sem autorização legislativa em desconforme com o art. 167 da Constituição Federal. Outro apontamento de 2010 e um ocorrido em 2012, indicaram falha também na abertura de créditos adicionais, nesse caso, pelo instrumento não ser Decreto do Executivo, violando os arts. 42 e 44 da Lei no 4.320/1964.

A terceira irregularidade de Planejamento / Orçamento, ocorrida em 2010 e uma das irregularidades ocorrida em 2012 foi a transferência de recursos de um órgão para o outro sem prévia autorização legislativa, contrariando o art. 167 da Constituição Federal. O último apontamento de 2010 foi a realização de despesas sem a existência de crédito orçamentário, indo contra o art. 167 da Constituição Federal. Mais um apontamento do assunto Planejamento / Orçamento, ocorrido em 2012, se deu pela abertura de créditos adicionais por conta de recursos inexistentes, em desacordo com o art. 167 da Constituição Federal e da Lei 4.320/1964 art. 43.

Silva (2010), em seu estudo sobre o novo papel dos Tribunais de Contas no julgamento das contas do governo, realizado em Fortaleza, foi destacado que é preciso haver melhoras nos gastos públicos desde o planejamento ao controle, para possam melhorar os resultados nos aspectos de eficiência, eficácia e efetividade.

As irregularidades em Licitação foram 14, sendo cinco de natureza grave ocorridas em 2010, uma ocorrida em 2011 de natureza grave, duas ocorridas em 2012 das quais uma é de natureza grave e a outra de natureza moderada, cinco de natureza grave ocorridas em 2013 e uma em 2014 também de natureza grave. Três irregularidades que aconteceram em 2010 e uma acontecida em 2013, foram ocasionadas pela divisão de despesas de um mesmo objeto, para modificar a modalidade de procedimentos licitatórios, em desacordo cos os arts. 23 e 24 da Lei 8.666/1993. Outro apontamento de 2010, o ocorrido em 2012 de natureza moderada e um ocorrido em 2013, aconteceram pela ocorrência de irregularidades nos procedimentos licitatórios. 
A quarta irregularidade sucedida em 2010, a de 2011, uma de 2012 e a de 2014, do assunto Licitação, aconteceram pela não-realização de processo licitatório previstos na Lei de Licitações. Uma das irregularidades que ocorreu em 2013, foi pela realização de despesas com justificativas de dispensa ou inexigibilidade de licitação sem amparo na legislação, infringindo os arts. 24 e 25 da Lei ${ }^{\circ}$ 8.666/1993. A quinta irregularidade ocorrida no ano de 2013, foi a ausência de justificativa para o não parcelamento de objeto divisível, como prevê os arts. 15 e 23, da Lei 8.666/1993. Incidiu também em 2013, uma irregularidade apontada pela realização de processo licitatório com preços superiores aos de mercado, em desacordo com o art. 37 da Constituição Federal.

Nos Contratos, foram 11 irregularidades apontadas, três de natureza grave ocorreram em 2010, uma de natureza moderada em 2011, três de natureza grave em 2012 e quatro também de natureza grave, ocorreram em 2013. Um apontamento de 2010 e um de 2013, indicam a ocorrência de irregularidades na execução dos contratos. Mais um apontamento de 2010 e um apontamento de 2013, dizem respeito a inexistência de acompanhamento e fiscalização da execução contratual, indo contra o art. 67 da Lei 8.666/1993. O último apontamento ocorrido em 2010, foi pela não-aplicação de sanções administrativas ao contrato em razão de atraso ou inexecução do contrato, o que vai contra os arts. 86 a 88 da Lei 8.666/1993.

Houve apontamentos do assunto Contrato no ano de 2011, um apontamento em 2012 e outro em 2013, que indicam a ocorrência de irregularidades na formalização dos contratos. Outro apontamento em 2012, diz respeito a prorrogação indevida de contrato de prestação de serviços, infringindo o artigo 57 da Lei 8.666/1993. No último apontamento de 2012, foi encontrado irregularidades no encerramento dos contratos. Um dos apontamentos de 2013, indica ocorrência de irregularidades nas alterações do valor contratual, conforme prevê os arts. 40 e 55 da Lei 8.666/1993.

As irregularidades do assunto Despesa foram 27, as quais onze ocorreram em 2010 todas de natureza grave, cinco em 2011 de natureza grave, sete em 2012 de natureza grave, três em 2013 sendo uma de natureza grave e duas de natureza moderada e uma em 2014 de natureza grave. Sete das irregularidades apontadas em 2010, uma apontada em 2011 e uma em 2012, indicam a realização de despesas não autorizadas, lesivas ao patrimônio público, que vai contra o art. 15 da Lei Complementar 101/2000. Dois outros apontamentos em 2010 e o apontamento de 2014, referem-se a pagamento de despesas referente a bens e serviços superiores ao valor contratado, conforme prevê o art. 37 da Constituição Federal. 
Ainda no ano de 2010, nas Despesas, há um apontamento de prestação de contas irregular de adiantamento; mais um apontamento do ano de 2010, um de 2011 e outro moderado de 2012, indicam prestação de contas irregular de diárias, em desconforme com o art. 37 da Constituição Federal. Em 2011, há um apontamento grave e em 2012 um moderado, de concessão irregular de diárias; ainda em 2011, foi apontado a realização de despesas sem emissão de empenho prévio, em desacordo com o art. 60 da Lei 4.320/1964. Houve pagamento de parcelas contratuais sem a regular liquidação, essa irregularidade refere-se a uma ocorrida em 2011, uma em 2012 e outra em 2013, infringindo o art. 63 da Lei 4.320/1964. Cinco irregularidades sucedidas em 2012 indicam falhas nas despesas, sem classificação específica do assunto.

No assunto Pessoal, foram apontadas 7 irregularidades; quatro são de natureza grave, que ocorreram em 2010 e três aconteceram em 2012, sendo uma de natureza grave e as demais sem classificação específica de natureza. Um apontamento de 2010 indica a contratação de pessoal por tempo determinado, burlando a exigência de realização de concurso público que fere o art. 37 da Constituição Federal. Mais uma irregularidade encontrada em 2010 e uma de 2012, referem-se a admissão de servidores acima do número de vagas previstas em lei, indo contra o art. 37 da Constituição Federal. Em 2010, ocorreu irregularidade na cessão e redistribuição de servidores públicos; houve apontamentos também, em desvio de função de Servidores Públicos, contrariando os princípios da legalidade e impessoalidade.

Macêdo e Costa (2014), concluíram que os destaques mais negativos, encontrados nos pareceres dos Tribunais de Contas do Brasil, foram os que envolveram gastos públicos com Pessoal, necessitando uma melhoria no controle interno para realização de concursos públicos.

Já os assuntos que ocorreram um menor número de irregularidades foi o Convênio e a Prestação de Contas, no assunto do Convênio, houve 2 apontamentos, sendo um no ano de 2010 que foi de natureza moderada e o outro em 2012 que foi de natureza grave. Essas irregularidades decorreram pela inobservância das regras de execução de convênios. As irregularidades cujo o assunto foi a Prestação de Contas foram apontadas 3, sendo todas de natureza grave, onde duas ocorreram em 2010 e a outra em 2011. Nesse assunto, a irregularidade sucedeu por sonegação de documentos e informações ao Tribunal de Contas. No estudo feito no município de Fortaleza, Silva (2010) destacou também, pontos positivos no assunto prestação de contas, onde ocorreu um número pequeno desse tipo de irregularidades. 


\section{CONSIDERAÇÕES FINAIS}

Com os resultados analisados do período de 2006 a 2014, pode então se averiguar que em alguns anos, houve um aumento significativo, comparado ao período anterior, de apontamentos de irregularidades nas contas públicas da UNEMAT, emitidos pelo TCE-MT. Em 2007 ocorreu uma irregularidade a mais que 2006, em 2010 foram dezessete apontamentos a mais que 2009 e 2012 ocorreram vinte e cinco irregularidades a mais que 2011. A partir daí, é possível constatar que as irregularidades ocorridas nesses anos, tem diminuído e aumentado em intervalos de um e dois períodos, ou seja, a quantidade de apontamentos tem oscilado nesses últimos anos.

É possível verificar que a maioria das irregularidades apontadas nesses anos, foram de natureza grave e a minoria, somente dois apontamentos, foram de natureza gravíssima. Verifica-se também que existem muitas falhas no Controle Interno da universidade, já que $36,07 \%$ dos apontamentos, indicaram irregularidades desse assunto, porém, nos dois últimos anos analisados, não foram apontados irregularidades de Controle Interno, significando que essas falhas vem sendo reparadas. As irregularidades de assunto Diversos, também tem sido maioria e vem melhorando ano a ano; e como as de Controle Interno, não houve apontamentos indicando irregularidades Diversas nos anos de 2013 e 2014.

Observando a quantidade de irregularidades que ocorreram no período analisado, não é possível identificar a quantidade exata de apontamentos que ocorreram durante cada gestão da universidade, pois os mandatos não tiveram início no dia primeiro de janeiro, portanto, o Tribunal de Contas passou a responsabilidade para os dois reitores que tiveram na gestão no período da auditoria.

Sendo assim, verifica-se que a gestão de Taisir Mahamudo Karin foi a que sucedeu mais apontamentos, totalizando em média 244 irregularidades o que equivale a 77,22\%. Já na gestão de Adriano Aparecido Silva, ocorreu em média 69 apontamentos, o que corresponde $21,83 \%$ do total de apontamentos e na gestão do reitor Dionei José da Silva houve em média 3 apontamentos totalizando $0,95 \%$. Vale ressaltar que foi somada as quantidades ocorridas durante os anos em que cada reitor esteve no cargo; nos anos em que houve duas gestões, foi somado a quantidade de irregularidades para o reitor que esteve mais meses na função.

Os objetivos da pesquisa foram atingidos, pois foi levantado a quantidade de apontamentos nos anos de 2006 a 2014 e feito as análises da natureza e assunto da 
irregularidade, podendo assim observar a evolução dos apontamentos do TCE-MT nas contas da UNEMAT.

Observando o quadro de apontamentos das irregularidades quanto ao assunto, concluise que o assunto de maior ocorrências, Controle Interno, apresentou uma redução significativa, além do item Diversos, que também melhorou, contribuindo sensivelmente na melhora nos números de apontamentos apresentados, expondo assim, uma melhor gestão administrativa e orçamentária da instituição.

Para futuras pesquisas, sugere-se o aprofundamento nos itens de apontamentos graves e gravíssimos, no sentido de verificar quais foram às falhas apresentadas e quais legislações foram afrontadas e que merecem maior atenção. Poderá ser pesquisado junto aos gestores, para saber as causas e os contextos nos quais as irregularidades apontam.

\section{REFERÊNCIAS}

ANDRADE, G. M; Estudo de Caso: Uma reflexão sobre a aplicabilidade em pesquisas no Brasil. Revista de Contabilidade e Organizações, São Paulo, v. 2, n. 2, p. 8-18, jan./abr. 2008. Disponível em: <http://www.redalyc.org/articulo.oa?id=235217215002>. Acesso em: 29 nov. 2016.

BEZERRA, M. N.; APOLINÁRIO, A. K. N. Accountability em Pareceres Prévios do Tribunal de Contas da Paraíba. In: XI CONGRESSO USR INICIAÇÃO CIENTÍFICA EM CONTABILIDADE, 2014 São Paulo. Anais... São Paulo: USP, 2014. Disponível em: <www.congressousp.fipecafi.org/web/artigos142014/475.pdf>. Acesso em: 19 ago. 2016.

BRASIL. Constituição (1988). Constituição da República Federativa do Brasil. Diário Oficial [da] República Federativa do Brasil. Brasília, 1988.

BRASIL. Lei n. 8.666, de 21 de junho de 1933. Dispõe sobre a instituição de normas para licitações e contratos da Administração Pública e dá outras providências. Disponível em: <http://www.planalto.gov.br/ccivil_03/leis/L8666cons.htm>. Acesso em 08 jan. 2016.

. Lei complementar $\mathrm{n}^{\circ}$. 101, de 04 de maio de 2000. Estabelece normas de finanças públicas voltadas para a responsabilidade na gestão fiscal. Diário Oficial [da] República Federativa do Brasil. Brasília, 2000. 


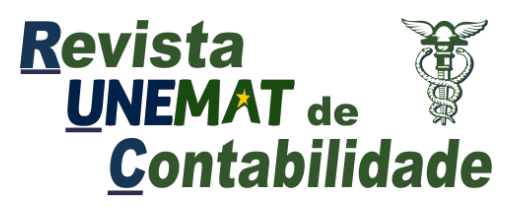

v. 9, n. 17,2020

CABRAL, R. A.; RIBEIRO, M. A. Análise dos Apontamentos do TCE-MT nas Contas Públicas dos municípios da região médio-norte do Mato Grosso. Revista UNEMAT de Contabilidade, Tangará da Serra, v. 1, n. 2, p. 30-53, jul./dez. 2012. Disponível em:

<http://www2.unemat.br/contabeistga/arquivos/anais_9secic.pdf>. Acesso em: 22 mar. 2016.

CAPOBIANCO, J. M. Composição e atribuições dos tribunais de contas no Brasil, 2012. Disponível em: <http://www.estudoadministracao.com.br/ler/16-11-2014-como-fazercitacoes-internet/>. Acesso em: 23 abr. 2016.

LOUREIRO, M. R.; TEIXEIRA, A. C.; PRADO, O. Construção de Instituições Democráticas no Brasil Contemporâneo: Transparência das Contas Públicas. Organizações e Sociedade, Salvador, v. 15, n. 47, p. 107-119, out./dez. 2008. Disponível em:

<http://www.redalyc.org/articulo.oa?id=400638303008>. Acesso em: 10 mar. 2016.

MACÊDO, F. F. R. R.; COSTA, I. C. D. S. Análise do conteúdo informativo dos pareceres dos auditores dos Tribunais de Contas dos Estados Brasileiros. Contexto, Porto Alegre, v. 14, n. 28, p. 83-99, set./dez. 2014. Disponível em:

<http://seer.ufrgs.br/index.php/ConTexto/article/viewFile/42931/pdf_36>. Acesso em: 19 mar. 2016.

MARTINS, H. H. T. S. Metodologia qualitativa de pesquisa. Educação e Pesquisa, São Paulo, v. 30, n. 2, p. 287-298, mai./ago. 2004. Disponível em:

<http://www.redalyc.org/articulo.oa?id=29830207>. Acesso em: 29 nov. 2016.

MATO GROSSO. Lei n. 269, de 22 de janeiro de 2007. Dispõe sobre a Lei Orgânica do Tribunal de Contas do Estado de Mato Grosso e dá outras providências. Disponível em: <http://www.tce.mt.gov.br/arquivos/downloads/00051757/LEI\%20ORG\%C3\%82NICA\%20\%20ATUALIZADA\%20AT\%C3\%89\%20JANEIRO\%20DE\%202015.pdf >. Acesso em: 12 ago. 2016.

MATO GROSSO. Tribunal de Contas do Estado. Identidade. Disponível em: <http://www.tce.mt.gov.br/conteudo/sid/767>. Acesso em: 03 abr. 2016.

MELO, V. V. D. Tribunal de Contas: história, principais características e importância na proteção do patrimônio público brasileiro. In: ÂMBITO JURÍDICO, 98, 2012 Rio Grande. Anais... Rio Grande: PUC, 2012. Disponível em:

<http://www.ambitojuridico.com.br/site/?n_link=revista_artigos_leitura\&artigo_id=11198> Acesso em 18 mai. 2016.

MENEZES, M. O Tribunal de Contas da União, controle horizontal de agências reguladoras e impacto sobre usuários dos serviços. Revista de Sociologia e Política, Curitiba, v. 20, n. 43, 
p. 107-125, out. 2012. Disponível em:

<http://www.redalyc.org/articulo.oa?id=23825528006>. Acesso em 05 fev. 2017

NETO, O. A. P. et al. Publicidade e Transparência das Contas Públicas: obrigatoriedade e abrangência desses princípios na administração pública brasileira. Contabilidade Vista e Revista, Minas Gerais, v. 18, n. 1, p. 75-94, jan./ mar. 2007. Disponível em: <http://www.redalyc.org/articulo.oa?id=197014728005>. Acesso em: 08 ago. 2016.

NETO, O. A. P.; CRUZ, F. D.; VIEIRA, A. L. Transparência das Contas Públicas: um enfoque no uso da Internet como instrumento de publicidade na UFSC. Revista

Contemporânea de Contabilidade, Florianópolis, v. 3, n. 5, p. 135-146, jan./jun. 2006. Disponível em: <http://www.redalyc.org/articulo.oa?id=76200508>. Acesso em: 10 mar. 2016.

RAMALHO, R. Dos Tribunais de Contas. Disponível em: $<$ http://www.webartigos.com/artigos/artigo-dos-tribunais-de-contas/56983/>. Acesso em: 18 mai. 2016.

SASSO, T. C. L.; TAMASO, R. C. M. Procedimentos metodológicos na construção do conhecimento científico: a pesquisa bibliográfica. Revista Katálysis, Florianópolis, v. 10, n. 1, p. 37-45, 2007. Disponível em: <http://www.redalyc.org/articulo.oa?id=179613967004>. Acesso em: 29 nov. 2016.

SILVA, A. A. D. O Novo Papel dos Tribunais de Contas no Julgamento das Contas de Governo - Considerações Sobre o Município de Fortaleza de 2005 a 2009. Disponível em: <http://portal.tcu.gov.br/lumis/portal/file/fileDownload.jsp?fileId>. Acesso em: 19 ago. 2016.

SILVA, C. A. T.; REVORÊDO, W. C. Economicidade da gestão pública municipal: um estudo das decisões do Tribunal de Contas do Estado de Pernambuco. Revista Universo Contábil, Blumenau, v. 1, n. 2, p. 9-22, mai./ago. 2005. Disponível em: <http://www.redalyc.org/articulo.oa?id=117015130002>. Acesso em: 10 mar. 2016.

SODRÉ, A. C. A. Lei de Responsabilidade Fiscal: Condição insuficiente para o ajuste fiscal. RAE-eletrônica, São Paulo, v. 1, n. 2, p. 1-15, jul./dez. 2002. Disponível em: <http://www.redalyc.org/articulo.oa?id=205118144010>. Acesso em: 08 ago. 2016.

VIEIRA, V. A. As tipologias, variações e características da pesquisa de marketing. Revista da FAE, Curitiba, v. 5, n. 1, p. 61-70, jan./abr. 2002. Disponível em: < http://sottili.xpg.uol.com.br/publicacoes/pdf/revista_da_fae/v5_n1_jan_abr_2002/as_tipologia s_variacoes_e_.pdf >. Acesso em: 29 nov. 2016. 